\title{
MASCULINIDADES E FEMINISMO: UM PERCURSO DE (DES)IDENTIDADES NA CRÔNICA DE ELIANE BRUM
}

\author{
Letícia Ueno Bonomo (Estudos Literários - UEL) ${ }^{1}$ \\ leticia.ub@gmail.com \\ Prof. Dr. Luiz Carlos Santos Simon (Orientador)
}

\section{RESUMO}

O objetivo deste artigo é analisar de que forma Eliane Brum, em seu texto Enfim, a emancipação masculina, publicada na obra A menina quebrada (2013), desconstrói as concepções de identidade e de gênero, as quais figuram um contexto de crise. A análise será feita, principalmente, sob a luz de teorias críticas pós-estruturalista. Servirão de base teórica as concepções de Judith Butler, Derrida, Hall, Connell, Jean-Jacques Courtine, etc. Os estudos feministas têm problematizado as condições das mulheres e desconstruído conceitos a fim de uma emancipação social e de direito. O que os estudos das masculinidades vêm fazer é reforçar a necessidade de desconstrução do conceito de "papéis" e, consequentemente, de gênero, partindo do pressuposto de que não há um "homem de verdade", conforme o ideal de "masculinidade hegemônica" tenta dar conta. O que se vive, segundo essas pesquisas, é uma crise da masculinidade, muitas vezes negada. Os estudos vão, portanto, totalmente ao encontro daquele que deve ser o maior objetivo dos estudos feministas: uma mudança de consciência e, consequentemente, de comportamento em relação às diferenças, sejam elas sexuais, de gênero, étnicas, culturais, de espécie, etc. Eliane Brum discute essas questões de forma acessível, o que torna o texto ainda mais interessante.

Palavras-chave: masculinidades, feminismo, identidade.

\section{A INDIZÍVEL REALIDADE E A ESTRUTURA LINGUÍSTICA}

Segundo o estruturalismo saussuriano, o signo é sempre arbitrário, ou seja, não há motivação alguma para sê-lo, é convenção histórica e cultural. Para o linguista, a relação entre signo, significante e significado é simétrica, ou seja, a linguagem seria uma estrutura demarcada entre códigos que se constituem a partir de um significante, o qual remete diretamente a um significado que só o é em oposição a outros significantes, caracterizando-se apenas pela diferença. Por exemplo: uma casa só é casa porque não é cama, cana, caso, etc. No entanto, isso quer dizer que um significado não está intrinsecamente presente no signo, uma vez que depende sempre daquilo que ele não é e, por isso, a significação está sempre ausente. No pós-estruturalismo, então, essa concepção de linguagem simétrica e dicotômica é posta em xeque. O significante passa a ser entendido separadamente do significado. E a linguagem, tendo em vista o modelo saussuriano, estaria mais para uma teia na qual os elementos não são absolutamente

\footnotetext{
${ }^{1}$ Mestranda do programa de pós-graduação em Letras - Estudos Literários, da Universidade Estadual de Londrina (UEL).
} 


\section{SEMINÁRIO DE PESQUISA EM CIÊNCIAS HUMANAS - SEPECH \\ Humanidades, Estado e desafios didático-científicos \\ Londrina, 27 a 29 de julho de 2016}

definíveis e onde tudo se relaciona. Dessa forma, não é possível pensar em uma linguagem estática, assim como não somos estáticos, visto que compostos por ela.

Partindo desse pressuposto e das concepções filosóficas ocidentais "fono" e "logocêntricas" sobre a linguagem, Jacques Derrida classifica como "metafísico" todo pensamento fundamentado em princípios inquestionáveis. Estes são geralmente definidos pelas "oposições binárias" (homem/mulher, verdade/falsidade, natureza/cultura, etc), as quais partem do princípio da exclusão (um deles é o princípio fundamental e o outro é o oposto excluído). Embora seja inevitável sermos atravessados por esse sistema, Derrida defende que é possível desconstruí-los, ou seja, operar criticamente a fim de enfraquecer parcial e/ou mutuamente essas dicotomias.

Terry Eagleton (1994) exemplifica uma aplicação desse binarismo importante para o que vou trabalhar adiante - no momento em que comenta a estreita relação entre homem e mulher, "compreendida" como o não-homem, o "outro", o oposto negativo. O que estreita essa oposição é o fato de que o homem só o é em contraposição a esse oposto: “[a] mulher não é apenas um outro ser, no sentido de alguma coisa fora de seu alcance, mas um outro intimamente relacionado a ele, a imagem daquilo que ele não é e, portanto, uma lembrança essencial do que ele é." (p.143). Assim, apesar de e devido à grande parte das organizações sociais serem dominada por homens (ainda supondo, aqui, a estabilidade do sexo binário):

Não só o seu próprio ser depende parasitariamente da mulher, e do ato de excluí-la e subordiná-la, mas também uma razão pela qual tal exclusão é necessária está no fato de que a mulher pode, afinal de contas, não ser um outro assim tão diferente. Talvez ela represente um signo de alguma coisa no homem que ele precisa reprimir, expulsar para além do seu próprio ser, [...] fora de seus próprios limites definitivos. Talvez o que esteja fora também esteja, de alguma forma, dentro, [...] de sorte que o homem precise policiar com atenção a fronteira absoluta entre as duas esferas, porque ela pode ser sempre atravessada, sempre foi atravessada e é muito menos absoluta do que parece. (EAGLETON, 1994, p. 143)

A partir da crítica pós-estruturalista, portanto, pôde-se observar que essas dicotomias estruturalistas tendem a limitar rigidamente, a partir de vieses ideológicos, o que é aceitável e o que não é. Tendo em vista essa corrente de pensamento, passam a figurar, juntamente, a crítica feminista e os estudos de gênero (dentro outros). $\mathrm{O}$ movimento e a crítica teórica feminista, considerados por Stuart Hall (2006) como o quinto descentramento identitário do sujeito cartesiano, indagou a distinção entre público e privado, questionou politicamente a vida social, politizou a subjetividade, a identidade e o processo de identificação. Antes de adentrar realmente na crítica feminista - e, consequentemente, aos estudos de masculinidades -, convém relembrar qual é a discussão de Hall a respeito de identidade.

Em $A$ identidade cultural na pós-modernidade, Hall expõe que, para alguns teóricos, a identidade moderna está entrando em colapso devido a mudanças estruturais significativas na sociedade no final do século XX. Se, no passado, tínhamos localizações sólidas enquanto indivíduos sociais, hoje, questões culturais como gênero, sexualidade, etnia, nacionalidade, etc, estão fragmentadas e transformando, também ou principalmente, nossa identidade pessoal. Abala-se, assim, a ideia de sujeito integrado, 


\section{SEMINÁRIO DE PESQUISA EM CIÊNCIAS HUMANAS - SEPECH \\ Humanidades, Estado e desafios didático-científicos \\ Londrina, 27 a 29 de julho de 2016}

o qual passa por um processo de deslocamento, ou descentração. Essa perda de sentido em si gera, então, a "crise de identidade". Sendo assim, é possível dizer que o ideal de sujeito cartesiano está para o estruturalismo saussuriano assim como a noção de sujeito pós-moderno está para a desconstrução pós-estruturalista (e derridiana). É a partir desse "espírito" de crise que passarei a analisar o texto de Eliane Brum.

\section{ENFIM, A DESCONSTRUÇÃO: AS (DES)IDENTIDADES PÓS-MODERNAS}

Ao narrar a ida de um engenheiro a um evento psicanalítico sobre "Masculinidade" para, então, debater sobre a "falta de lugar [do homem] no mundo" (BRUM, 2013, p.285) - grifo meu -, a crônica de Eliane Brum, Enfim, a emancipação masculina, pode ser considerada uma desconstrução em forma de texto narrativo. A cronista mostra que "a melhor notícia para todos nós é a confusão sobre o lugar do homem" (p. 285). Essa constatação faz lembrar Kobena Mercer (1990), ao elucidar que "a identidade somente se torna urna questão quando está em crise, quando algo que se supõe como fixo, coerente e estável é deslocado pela experiência da dúvida e da incerteza" (apud HALL, 2006, p.1). Partindo do mesmo pressuposto, Kimmel (1998) declara que "[é] um luxo que somente pessoas brancas em nossa sociedade não pensem sobre raça a cada minuto de suas vidas. É um luxo que somente homens em nossa sociedade façam de conta que o gênero não importa" (p. 106). Assim, a motivação do otimismo de Brum se torna mais claro. Contudo, há quem questione porque é importante que se discuta o lugar do homem, e não apenas da mulher. Não seria ele gozador de privilégios o suficiente?

Bom, em primeiro lugar, faz-se necessário que se compreenda os estudos das masculinidades. Ao discutir o "lugar do homem", não se trata trabalhar uma identidade unificada. De acordo com Connell e Messerschmidt (2013):

O conceito de masculinidade hegemônica formulado há duas décadas influenciou consideravelmente o pensamento atual sobre homens, gênero e hierarquia social. Esse conceito possibilitou uma ligação entre o campo em crescimento dos estudos sobre homens (também conhecidos como estudos de masculinidade e estudos críticos dos homens), ansiedades populares sobre homens e meninos, posição feminista sobre o patriarcado e modelos sociais de gênero. Encontrou uso em campos aplicados que variam desde a educação ao trabalho antiviolência até a saúde e o aconselhamento. (p.241-242)

Tendo isso em vista, nota-se que os estudos das masculinidades não são fixados em um comportamento masculino padrão, a fim de reforçá-lo. Pelo contrário, pesquisadores que optam por trabalharem a partir desse conceito visam à desconstrução da ideia de norma, totalmente ligada às discussões de gênero desenvolvidas pelos estudos feministas. Por conta disso, os termos "masculinidades" e "virilidade" precisam ser diferenciados. Enquanto o primeiro remete às várias possibilidades de comportamentos e ações masculinos, por exemplo, a uma masculinidade plural, o segundo suprime qualquer pluralidade e restringe o conceito a um ideal de força física, firmeza moral e potência sexual. Para Connell e Messerschmidt, "As masculinidades são configurações de práticas que são realizadas na ação social e, dessa forma, podem se 


\section{SEMINÁRIO DE PESQUISA EM CIÊNCIAS HUMANAS - SEPECH \\ Humanidades, Estado e desafios didático-científicos \\ Londrina, 27 a 29 de julho de 2016}

diferenciar de acordo com as relações de gênero em um cenário social particular." (2013, p.250). Ou seja, cada prática social das relações de gênero pode estar ligada a essa pluralidade do masculino, como: a violência, a paternidade, a educação, a vida afetiva e sexual (hetero, homo ou trans), etc. Partindo desse ponto de vista, ao retomar a história da virilidade, Courtine (2013) aponta para a possível crise do "poder viril" em um mundo pós-guerra, industrializado e urbanizado. Poder que se vê confrontado pelos avanços feministas, entre 1960 e 1970, que, consequentemente, redirecionaram os "papéis" sexuais tanto na esfera pública quanto na esfera privada. Nesse cenário, o "modelo arcaico dominante" se vê, ainda, angustiado. Afinal, o que é ser homem?

Em segundo lugar, se ainda vivemos em uma sociedade falogocêntrica, violenta, especista, etc, ainda que movimentos sociais lutem por seu lugar, é preciso que essa ideia de identidade masculina ocidental, construída e petrificada por milhares de anos, seja finalmente desconstruída, a fim de que concepções como essas caiam por terra ou sejam, ao menos, amenizadas. Afinal, é a ideia de centro, de unificação, de hegemonia que nos limita. É por isso que a crônica escolhida para análise se faz tão importante. Ela discute, narrativamente, crítica teórica, sem ter necessariamente esse interesse - aliás, acredito realmente que não haja esse interesse -, de forma no mínimo provocativa, se não esclarecedora. E, devido ao fato de ter tido, a priori, a coluna jornalística como ambiente de circulação, a crônica provavelmente atingiu um público considerável de leitores. Leitores esses que talvez nunca houvessem se questionado a respeito de suas identificações.

A cronista aborda a figura de Laerte, cartunista reconhecido e, segundo ela, "uma revolução encarnada numa pessoa" (p.285). É justamente por isso que ele é trazido para o texto. A "emancipação masculina" de que fala a autora está relacionada com a libertação de moldes culturais obsoletos, unificados, estáveis, os quais são postos por ela como uma prisão disfarçada de vantagem. Enquanto apresenta o cartunista aos leitores, defende, em sua narrativa, uma nova percepção da vida social. Ela explica que Laerte, em 2010, passou a se apresentar publicamente vestido de mulher, mas que isso não diz, necessariamente, que ele seja gay:

(...) Laerte se coloca para além das definições. Nem acho que crossdresser (...) serve para enquadrá-lo. Acho que tonos nós ganharíamos 'héteros, gays, bissexuais, transgêneros, travestis, transexuais, assexuais etc etc' - se abolíssemos a necessidade de caber em algum verbete. (...) A única definição que vale a pena é justamente a indefinição. Sou aquele/a que é sem se dizer. Ou sou aquele/a que é sem precisar dizer o que é. (p. 286)

Não há como não se lembrar de Judith Butler e os "Problemas de gênero" (2015), em um dos momentos no qual ela questiona a ordem compulsória de sexo, gênero e desejo:

Se o caráter imutável do sexo é contestável, talvez o próprio construto chamado "sexo" seja tão culturalmente construído quanto o gênero; a rigor, talvez o sexo sempre tenha sido o gênero, de tal forma que a distinção entre sexo e gênero revela-se absolutamente nula. (...) Resulta daí que o gênero não está para a cultura como o sexo está para a natureza; ele também é meio discursivo/cultural pelo qual "a natureza 


\section{SEMINÁRIO DE PESQUISA EM CIÊNCIAS HUMANAS - SEPECH \\ Humanidades, Estado e desafios didático-científicos \\ Londrina, 27 a 29 de julho de 2016}

sexuada" ou "um sexo natural" é produzido e estabelecido como "prédiscursivo" (p. 27).

De forma bastante perspicaz, Butler questiona uma ideia, até então, consensual entre os estudos feministas: o gênero apenas como construção cultural. Para ela, são os limites da análise discursiva, estabelecida e baseada em estruturas binárias, que constituem o domínio imaginável do gênero. A fim de melhor esclarecer, Butler caracteriza gênero como "performativo", ou seja, "não há identidade de gênero por trás das expressões de gênero", pois ela "é performativamente construída, pelas próprias expressões tidas como seus resultados" (p.56). Dessa forma, é possível perceber que a atitude de Laerte em relação à sua identidade está muito mais relacionada à ideia de gênero enquanto "performance", uma vez que nada existe antes da ação e, portanto, de acordo com esse conceito, ele pode ser o que quiser. Para esclarecer um pouco mais sobre o artista e sua dinâmica, Brum observa que:

[e]ssa é a novidade de Laerte, que é homem, é mulher, é masculino, é feminino e é também alguma coisa além ou aquém disso. Que se veste de mulher, mas fala e caminha como um homem. Que na infância gostava de costura e futebol. Que vai jantar de saia e unhas vermelhas com uma namorada, mas pode também ter um namorado. (...) Laerte é novo/a porque nos escapa. É um homem novo, mas também pode ser uma mulher nova (p. 286).

Toda essa análise que a cronista acaba por fazer é fruto de uma entrevista concedida pelo cartunista à Roda Viva, na TV Cultura. Em determinado momento da entrevista, conta a autora, Laerte revela uma percepção sagaz a respeito da condição do homem (aqui, e em outras partes do texto, ao utilizar o termo "homem", refiro-me ao "sexo masculino", apenas para facilitar a fluidez da análise, embora tenha consciência de que tanto "homem" quanto "sexo masculino" sejam problemáticos, assim como "mulher" e "sexo feminino"). Ele comenta que já existiu uma revolução feminina, que é um marco da humanidade, e a autora explica que ele referia-se aos direitos e às inovações que as mulheres conseguiram a partir disso; porém, observa ele, ainda não aconteceu uma revolução masculina. Percebendo onde ele queria chegar, Brum continua sua reflexão e comenta sobre o fato de que "Marlene Dietrich, por exemplo, causou comoção por usar calças, mas isso em 1920! Quase um século depois, Laerte nos empapa de assombro por ir ao supermercado de saia. Isso diz alguma coisa, não?" (p.287). A crônica, porém, não se encerra em problematizar o vestuário que compete ou não aos "homens". Esse é o mote da autora para entrar no que realmente interessa: o novo processo de identificação social.

Eliane Brum desenvolve todo um raciocínio a respeito da "crise do masculino", sem necessariamente usar a expressão. Começa comentando que não deve ser fácil ser homem, nos dias de hoje, uma vez que não se sabe mais o que seja isso. Observa que, a princípio, nunca foi preciso uma revolução masculina, pois os homens já tinham, supostamente, seus direitos garantidos. Essa situação é vista por ela como aparentemente cômoda, afinal: "[p]odiam fazer o que bem entendiam. Desde quem fossem 'homens'. E aí é que morava - e ainda mora, em muitos casos - a prisão. Podiam tudo, desde que fossem uma coisa só" (p. 287). Ser "homem de verdade", ou seja, viril, era - e ainda é, de certa forma - a regra do jogo. Esse comportamento deveria 


\section{SEMINÁRIO DE PESQUISA EM CIÊNCIAS HUMANAS - SEPECH \\ Humanidades, Estado e desafios didático-científicos \\ Londrina, 27 a 29 de julho de 2016}

se basear em um ideal de força física, firmeza moral e potência sexual, encarado, não só pela autora, como um "peso incomensurável":

O privilégio masculino é também uma armadilha [...] que impõe a cada homem o dever de afirmar, em qualquer circunstância, a sua virilidade [...]. A virilidade, entendida como capacidade reprodutiva, sexual e social, mas também como aptidão para o combate e para o exercício da violência, é antes de tudo uma carga. Tudo concorre para fazer do ideal da impossível virilidade o princípio de uma imensa vulnerabilidade. (BOURDIEU apud COURTINE, 2012, p. 11-12)

Tendo em vista que, atualmente, não há uma definição do que é ser homem - e, igualmente, não se define o que é ser mulher -, esse modelo arcaico dominante, pregado durante séculos, está em crise. Essa crise nada mais é do que consequência da "crise de identidade" discutida por Hall (2006), o qual explica que: "[o] sujeito, previamente visto como tendo uma identidade unificada e estável, está se tornando fragmentado; composto não de uma única, mas de várias identidades, algumas vezes contraditórias ou não- resolvidas" (p. 2). A cronista, como se esclarecesse teoricamente o fato, comenta que essas definições são impossíveis, "[d]o mesmo modo que a anatomia também não é mais capaz de definir o que é ser um homem e o que é ser uma mulher. (...) Se há algo que define (...), este algo está fora das palavras” (p. 288). É nítida a relação desse pensamento com as críticas de Butler e Derrida. Butler discute, como já visto, o caráter imutável do sexo e problematiza, influenciada por Derrida, a noção de linguagem, aquela que costuma repousar em uma significação unívoca, que é falocêntrica e que se apresenta como a racionalidade universal. Para Derrida (1973) este é o grande problema da linguagem, e do conceito ocidental de linguagem: a metafísica que tenta determinar sua infinitude, limitar seu campo de atuação.

Após debater os processos de identificação, Brum aponta que essas transformações são frutos da revolução feminina e dos homens que se permitiram contrariar os padrões - como bem observou, a partir da crítica teórica, Hall (2006) e Courtine (2012). Como consequência, os "homens" lamentam sua perda de lugar, o seu deslocamento. Dessa forma, ao trabalhar a ideia de virilidade fascista, Haroche (2012) cita Theweleit (2007) para argumentar sobre o aprendizado da "potência viril":

[A] carapaça do corpo (...) se ergue não somente contra uma exterioridade ameaçadora, contra as representações dominadas pelo 'movimento' da realidade, a feminilidade voraz (...), mas também contra a própria interioridade corporal do soldado macho, ameaçado pela fragmentação. (p. 27)

A busca contemporânea por esse ideal de virilidade impossível gera angústia. Agora que a face vulnerável do masculino não pode mais ser ocultada e as mudanças no processo de identificação estão escancaradas, só restam duas opções: ou a crise, ou a emancipação. Alguns dos que, em crise, optam por sua negação e prezam pelo modelo arcaico dominante, muitas vezes escolhem a violência como forma de conter as masculinidades que destoam desse modelo: "Sem saber o que fazer da existência nem de si, alguns arrotam alto ou espancam gays na tentativa pífia de mostrar que ainda sabem o que são" (BRUM, 2013, p. 288). 


\section{SEMINÁRIO DE PESQUISA EM CIÊNCIAS HUMANAS - SEPECH \\ Humanidades, Estado e desafios didático-científicos \\ Londrina, 27 a 29 de julho de 2016}

Além dessas constatações, Brum instiga a necessidade de uma mudança real tanto nos homens quanto nas mulheres (novamente, esclareço que o uso dos termos está sendo feito apenas visando à fluidez da análise).

Aos homens:

Perder o lugar e confundir-se não é fácil, não é mesmo. Mas é um espaço inédito de liberdade. É possível arrancar o terno de chumbo e descobrir que pele existe embaixo dele. E faz parte estar ainda em carne viva. Acho que os homens alcançaram, finalmente, um começo de emancipação. (BRUM, 2013, p. 288).

Às mulheres:

E espero que as mulheres tenham a grandeza de estar à altura desses novos homens que começam a surgir. E enfiem a saudade do macho provedor na lata de material reciclável. Porque há muitas mulheres que ainda suspiram de nostalgia do macho provedor, mesmo se achando modernas e liberadas. Pode até ser que seja um bom arranjo para alguém, mas já não há garantias (BRUM, 2013, p. 288).

Provocativa, Eliane Brum quebra com uma prática bastante recorrente: a vitimização, apenas, daquele grupo que está em suposta desvantagem - no caso dos estudos de gênero, o modelo dominante seria, resumidamente, o homem branco e heterossexual - ao invés da problematização. A cronista problematiza tanto as concepções de gênero e sexo quanto a atitude de homens e mulheres diante dessas novas configurações. Não há, no texto, uma sobreposição de identidades ou identificações, uma vez que essa prática contrariaria o que a autora procurou (des)construir ao longo de sua narrativa.

\section{CONSIDERAÇÕES FINAIS}

A crônica de Eliane Brum mostra-se bastante relevante para o que se quer nos estudos feministas: transformação de consciência e atitude em relação às diferenças - no caso da narrativa, especificamente as de gênero. Devido à linha tênue que ocupa enquanto gênero textual jornalístico e literário, além do meio em que foi primeiramente veiculada (a revista Época), a crônica da autora dá conta de um público variado. E provoca-o a repensar sua condição enquanto homem e mulher. $\mathrm{O}$ interessante disso é ver como se tornou acessível a (des)construção de um pensamento sobre sexo, gênero, identidade, etc. Enquanto, muitas vezes, debates profundos sobre as questões permanecem no meio acadêmico, a narrativa de Brum percorre teorias e críticas, ainda que sem esse propósito, mantendo a leveza característica desse gênero textual.

A contribuição do movimento feminista e, consequentemente, da crítica teórica feminista, é considerável no que tange à ampliação "da área política ou do politizável" (BOURDIEU, 2002, p. 69). Além disso, os estudos das masculinidades vão totalmente ao encontro desse movimento. A partir da narrativa em questão, percebe-se que, nos estudos de gênero, só faz sentido falar em mulher se falarmos em homem, e vice-versa. Afinal, para o desaparecimento progressivo da dominação masculina e o 


\section{SEMINÁRIO DE PESQUISA EM CIÊNCIAS HUMANAS - SEPECH \\ Humanidades, Estado e desafios didático-científicos \\ Londrina, 27 a 29 de julho de 2016}

avanço da igualdade de direitos, faz-se necessária uma ação política que leve em consideração todos os efeitos de dominação, inclusive do homem para o próprio homem. Os estudos das masculinidades levam a crer que é o aprendizado da "potência viril" o que provoca um círculo vicioso e perpetua tanto o modelo arcaico quanto a dominação proveniente desse modelo.

Também estão presentes na crônica apontamentos para uma concepção pósestruturalista de linguagem, a qual é essencial às discussões de gênero, pois contribui para compreensão e posterior desconstrução de paradigmas que envolvem as questões de dominação. Ademais, o entendimento de que não existe identidade plena, mas processos de identificação, é imprescindíveis para que diferentes possibilidades sejam aceitas e encaradas como tão legítimas quanto qualquer outra aparentemente predominante. E esse entendimento percorre todo o texto da autora. Psicanaliticamente, continuaremos buscando uma "identidade una", construindo biografias, juntando partes divididas de nossos "eus", afinal, fantasiamos a plenitude e essa ideia é prazerosa. No entanto, tentar encaixar o outro dentro de uma identidade acolhida como verdadeira vai além do "bel-prazer" e, por isso, Brum defende que é preciso libertar-se. Enfim, a emancipação masculina é uma narrativa que explora um percurso de (des)identidades na modernidade tardia, suas consequências, e aponta para novos caminhos. Para uma real emancipação, a autora deixa a dica: "Na vida, não limite-se. Laerte-se!” (p. 289).

\section{REFERÊNCIAS}

BOURDIEU, Pierre. A dominação masculina. Rio de Janeiro: Bertrand Brasil, 2002.

BRUM, Eliane. A menina quebrada. Porto Alegre: Arquipélago Editorial, 2013.

BUTLER, Judith P. Problemas de gênero: feminismo e subversão da identidade. Rio de Janeiro: Civilização Brasileira, 2015.

CONNELL, R. W; MESSERSCHMIDT, J. W. Masculinidade hegemônica: repensando o conceito. Estudos Feministas, Florianópolis, 21(1): 241-282, jan.- abr. 2013. Disponível em: $<$ https://periodicos.ufsc.br/index.php/ref/article/view/S0104026X2013000100014>. Acesso em: 10 mar. 2016.

COURTINE, Jean-Jacques. "Impossível virilidade". A virilidade em crise? Séculos XX$X X I$. CORBIN, Alain; COURTINE, Jean-Jacques; VIGARELLO, Georges. v.3 de História da virilidade. COURTINE, Jean-Jacques (org.). Tradução Noéli Correia de Mello Sobrinho e Thiago de Abreu e Lima Florêncio. Rio de Janeiro: Vozes, 2013.

DERRIDA, Jacques. Gramatologia. São Paulo: Perspectiva, 1973.

EAGLETON, Terry. Teoria da literatura: uma introdução. São Paulo: Martins Fontes, 1994.

HALL, Stuart. A identidade cultural na pós-modernidade. Rio de Janeiro: DP\&A Editora, 2006. 


\section{SEMINÁRIO DE PESQUISA EM CIÊNCIAS HUMANAS - SEPECH \\ Humanidades, Estado e desafios didático-científicos \\ Londrina, 27 a 29 de julho de 2016}

HAROCHE, Claudine. "Antropologias da virilidade: o medo da impotência". $A$ virilidade em crise? Séculos XX-XXI. CORBIN, Alain; COURTINE, Jean-Jacques; VIGARELLO, Georges. v.3 de História da virilidade. COURTINE, Jean-Jacques (org.). Tradução Noéli Correia de Mello Sobrinho e Thiago de Abreu e Lima Florêncio. Rio de Janeiro: Vozes, 2013.

KIMMEL, Michael. A produção simultânea de masculinidades hegemônicas e subalternas. In: Horizontes antropológicos. Porto Alegre, ano 4, n. 9, out. 1998. 